\title{
Becoming a Sport Psychologist
}

\author{
P. McCarthy y M. Jones (2014). New York: Routledge
}

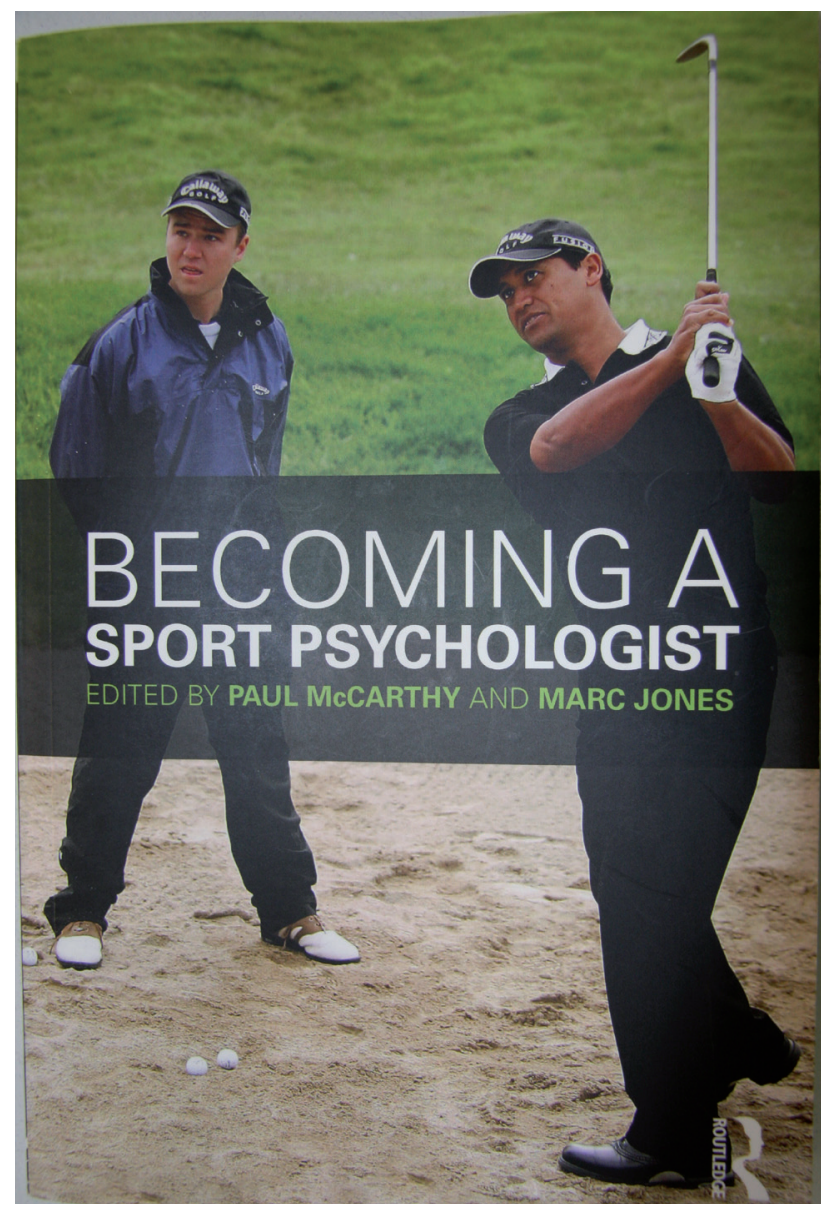

La investigación en el ámbito de la psicología del deporte está bien asentada y dispone de un amplio recorrido histórico desde aquel primer experimento de Triplett (1898), sin embargo la práctica profesional no dispone del mismo recorrido temporal por obvia que pueda ser la vocación aplicada de la disciplina (Weinberg y Gould, 1996).

Mientras se trabaja para el reconocimiento profesional de los psicólogos del deporte mediante una acreditación que implique como requisito la necesaria formación teórica y práctica, sigue siendo difícil para los que empiezan su trayectoria laboral en este campo -y también para los que aspiran a estabilizarla- saber qué competencias deben desarrollar o qué caminos les acercarán al sueño: ser psicólogo del deporte. Dosil y Garcés de los Fayos (2010) adelantaban parte de la respuesta desvelando las competencias necesarias para alcanzar el éxito en este ámbito, entre las que se incluyen habilidades de autogestión, de administración de procesos laborales y de manejo social del entorno. En esta ocasión, Paul McCarthy y Marc Jones pretenden con Becoming a Sport Psychologist incidir en los procesos de aprendizaje y transformación personal necesarios para desarrollar esas competencias desde la óptica de las experiencias personales de profesionales de reconocido prestigio a los que ceden los diferentes capítulos del libro.

La obra, siguiendo esta filosofía del "cómo lo hizo", repasa en primera persona los procesos más o menos azarosos que siguieron en su construcción profesional expertos provenientes de la psiquiatría, la educación física (con Robert Weinberg como figura destacada, manejando su proceso en base a la adaptación a las demandas cambiantes de un mismo cliente/ jefe), la asesoría psicológica, la psicología básica (gracias a la visión crítica, por ejemplo, de Mark B. Andersen acerca de la propia profesión y sus formatos de intervención), la psicología clínica (interesante la aportación de Ronald E. Smith acerca del interés de algunos entrenadores por deportes minoritarios en los que los padres no supieran lo suficiente para adoptar un rol de "entrenador en la banda") o las ciencias del deporte (desde cuya perspectiva nos asomamos a las rutinas personales y laborales -por ejemplo- de Zoe Knowles, quien aporta respuesta a las eternas preguntas: ¿̨oy bueno en lo que hago?, ¿cómo puedo evaluarlo?).

Finalizar la lectura de los diecinueve capítulos de Becoming a Sport Psichologist permite al lector acercarse al verdadero sentido del deporte, ese que queda reflejado en el credo olímpico y reza "lo importante no es haber vencido sino haber luchado bien". Todos los procesos personales que se recogen tienen tres cosas en común que, quizás, sean el denominador común a seguir en la construcción del desempeño profesional del psicólogo del deporte:

1) Asunción de riesgos profesionales, que incluyen desde trabajo en segundos (y terceros) idiomas hasta desarrollo de proyectos con mínimo soporte o la apuesta por ideas y metodologías novedosas.

2) Enfoque atencional centrado en el conocimiento de aquellos con lo que se trabaja, sus demandas, intereses y necesidades. Las creencias y emociones -miedos habitualmente- del psicólogo quedan relegados a un segundo plano, los beneficios derivados de la intervención también.

3) Vocación multidisciplinar, en la que la información entre los profesionales fluye de manera natural; en la que 
los tiempos, espacios y tareas se comparten en beneficio del deportista.

Así, Becoming a Sport Psychologist se convierte en una fructífera lectura para los psicólogos del deporte: permitirá a los que se inician vislumbrar la senda que se abre ante ellos, ayudará a los que luchan por caminar dentro del recorrido a acercarse a otras metodologías e incluso hacer suyas algunas ideas, recordará a los que ya pasean en esta travesía la emoción de crear una nueva bifurcación.
Dosil, J. y Garcés de los Fayos, E. J. (2010). Ser psicólogo del deporte. 10 competencias para la excelencia profesional. A Coruña: Netbiblo.

Triplett, N. (1898). The dynamogenic factors in peacemaking and competition. American Journal of Psychology, 9, 507-533.

Weinberg, R. S. y Gould, D. (1996). Fundamentos de psicología del deporte y el ejercicio fisico. Barcelona: Ariel.

Recensiona:

M Rocío Bohórquez Gómez-Millán 